OPEN ACCESS

Edited by:

Jennie Cecile Brand-Miller

University of Sydney, Australia

Reviewed by:

María Teresa García-Conesa, Center for Edaphology and Applied Biology of Segura, Spanish National

Research Council, Spain

Michael Skilton,

The University of Sydney Central

Clinical School, Australia

${ }^{*}$ Correspondence:

Rashmi Ranjan Das

rrdas05@gmail.com

Specialty section

This article was submitted to

Nutrition and Metabolism,

a section of the journal

Frontiers in Nutrition

Received: 28 October 2019

Accepted: 02 March 2020

Published: 31 March 2020

Citation:

Das RR, Mangaraj M, Panigrahi SK,

Satapathy AK, Mahapatro $S$ and

Ray PS (2020) Metabolic Syndrome

and Insulin Resistance in

Schoolchildren From a Developing

Country. Front. Nutr. 7:31

doi: 10.3389/fnut.2020.00031

\section{Metabolic Syndrome and Insulin Resistance in Schoolchildren From a Developing Country}

\author{
Rashmi Ranjan Das ${ }^{1 *}$, Manaswini Mangaraj ${ }^{1}$, Sandeep Kumar Panigrahi ${ }^{2}$, \\ Amit Kumar Satapathy ${ }^{1}$, Samarendra Mahapatro ${ }^{1}$ and Partha Sarathi Ray ${ }^{1}$ \\ ${ }^{1}$ Department of Pediatrics and Biochemistry, AlIMS, Bhubaneswar, India, ${ }^{2}$ Department of Community Medicine, IMS and \\ SUM Hospital, Siksha 'O' Anusandhan deemed to be University, Bhubaneswar, India
}

Background: Overweight and obesity are prevalent in schoolchildren due to dietary habits and lack of exercise. These children are prone to metabolic syndrome (MS) and future risk of type 2 diabetes mellitus and cardiovascular diseases.

Materials and Methods: This cross-sectional study was conducted in Bhubaneswar City, Eastern India, among schoolchildren. Obesity and overweight were determined by the Indian Academy of Pediatrics guideline. Fasting venous blood samples were taken for insulin, blood glucose, and lipid levels measurement. Blood pressure was measured as per the protocol. The International Diabetic Federation (IDF) criteria for the definition of MS were followed. Insulin resistance was determined by a homeostatic model assessment (HOMA-IR).

Results: A total of 1,930 children were screened, of which 545 (28.2\%) were overweight and obese. The male to female ratio was 1.27. The overall prevalence of MS was $21.8 \%$ ( $11 \%$ in 6 to $\leq 10$ years old and $30.6 \%$ in 11 to 16 years old). A history of cardiovascular disease, diabetes, obesity, and hypertension in the family was present in $42.7 \%$. Acanthosis nigricans was present in $46.4 \%$. A history of exclusive breast feeding for 6 months was present in 68.1\%. The mean HOMA-IR in children with MS was 5.46 compared to 2.18 in those without MS (insulin resistance was more common in children with MS).

Conclusions: The present study found a higher prevalence of MS and insulin resistance in schoolchildren from Eastern India who are overweight/obese.

Keywords: obesity, overweight, cross-sectional study, metabolic syndrome, HOMA-IR

\section{INTRODUCTION}

Schoolchildren nowadays have increased prevalence of overweight and obesity due to lack of exercise and improper dietary habits. Besides the high-income countries, the prevalence is increasing in low- and middle-income countries. In 2016, as per the World Health Organization (WHO), 41 million children under 5 years old were overweight or obese (1). Nearly $50 \%$ of them were under 5 years old and lived in Asia. Over 340 million children and adolescents over 5 years old were overweight or obese (1). The prevalence of overweight or obesity in the latter age group has increased dramatically from $4 \%$ (in 1975) to $>18 \%$ (in 2016) with a nearly equal proportion among 
both sexes (18\% in girls and $19 \%$ in boys) (1). Regarding obesity, the prevalence in this age group was $<1 \%$ in 1975, but in 2016 it has increased to $>124$ million (6\% of girls and $8 \%$ of boys) (1).

In a systematic review on overweight and obesity in the Indian subcontinent using the International Obesity Task Force (IOTF)Cole et al. criteria, the pooled prevalence of obesity in children under 5 years old was $<2 \%$, while in those over 5 years old (not adolescents) it was 2 to $8 \%(2,3)$. Among the adolescents, the prevalence of overweight was 3.0 to $24.7 \%$, and obesity was 1.5 to $14 \%(2,3)$.

Overweight and obesity are linked to more deaths worldwide than underweight. Globally, there are more people who are obese than underweight-this occurs in every region except in parts of sub-Saharan Africa and Asia. Children with obesity are prone to metabolic syndrome (MS) and future risk of type 2 diabetes mellitus and cardiovascular diseases. Although there are many reports on children with obesity, there is paucity of data on children affected with MS from settings in developing countries. Our primary objective was to determine the prevalence of MS in schoolchildren with overweight/obesity. Our secondary objectives was to determine the prevalence of overweight/obesity and insulin resistance in these children.

\section{MATERIALS AND METHODS}

This school-based cross-sectional study was conducted in Bhubaneswar City, Eastern India, over a 1-year period (April 2017 to March 2018). Schoolchildren 6 to 16 years of age were included. The exclusion criteria were major medical illness including diabetes mellitus, physical deformity, chronic medication use that can cause overweight/obesity/metabolic syndrome, and unwillingness to participate in the study. Cluster random sampling method was used with the cluster being schools. A trained research officer made school visits under the supervision of the principal investigator. After obtaining permission from the school principal, the participant information sheets and informed consent documents were distributed to the schoolchildren to be read in detail by the parents at home and brought back on the next day. Clarifications from the parents regarding the study, if any, were given through telephonic contact with the research team.

Anthropometric measurements including height, weight, waist, and hip circumference were obtained. Height (taken with the schoolchildren not wearing their shoes) was measured with a stadiometer to the nearest centimeter $(\mathrm{cm})$. Weight was measured to the nearest $100 \mathrm{~g}$, with the schoolchildren wearing light clothing but without shoes. Waist circumference $(\mathrm{WC}, \mathrm{cm})$ was measured, with the schoolchildren in a standing position, using a non-stretchable measuring tape at midpoint between the costal margin and iliac crest in the mid-axillary line at the end of expiration. Hip circumference $(\mathrm{cm})$ was measured at the prominence of the buttocks. Blood pressure (BP) was measured with a standardized sphygmomanometer with appropriately sized cuffs. BP was measured in the right arm, in sitting position, three times (at 0-, 5-, and 30-min intervals), and the average of the readings was taken. Body mass index (BMI) was calculated $\left(\mathrm{kg} / \mathrm{m}^{2}\right)$ as per the standard formula and classified into overweight or obesity as described previously (4). Fasting venous blood samples of eligible children were taken for insulin, blood glucose, triglyceride, and low density lipoprotein (LDL) and high density lipoprotein (HDL) cholesterol measurement, and the abnormalities were defined as per the data published in Indian children previously $(5,6)$. Plasma glucose was obtained by the glucose oxidize technique, and serum lipids were measured with a Beckman Coulter (AU5800 Clinical Chemistry Analyzer, Danaher Corporation, California, USA). Serum insulin level was determined with a Beckman Coulter (Access 2 Immunoassay System, Danaher Corporation, California, USA). At the same time, data on age, gender, birth weight, exclusive breastfeeding (EBF) in the first 6 months, and family history of cardiovascular disease (CVD)/non-communicable diseases (NCD)/type 2 diabetes/ hypertension in the family (first- and second-degree relatives) were recorded. Waist and hip circumference cutoffs were defined as per the previously published guideline in Indian children (7). Hypertension was defined as per the international guideline published by the American Academy of Pediatrics (8). Physical examination was done for the presence of acanthosis nigricans (on the neck, axillae, and skin folds) and hepatomegaly.

The International Diabetic Federation (IDF) criteria for the definition of metabolic syndrome were followed in children $>10$ years of age (9). The IDF criteria defines MS as the presence of obesity (WC $\geq 90$ th centile or adult cutoff if lower) plus two or more risk factors [fasting blood glucose (FBG) $\geq 100 \mathrm{mg} / \mathrm{dl}$ or type 2 diabetes mellitus, elevated blood pressure defined as systolic $\mathrm{BP}(\mathrm{SBP}) \geq 130 \mathrm{mmHg}$ or diastolic $\mathrm{BP}(\mathrm{DBP}) \geq 85$ $\mathrm{mmHg}$, and dyslipidemia defined as triglyceride $(\mathrm{TG}) \geq 150$ $\mathrm{mg} / \mathrm{dl}$ or HDL $<40 \mathrm{mg} / \mathrm{dl}$ ]. In children who were overweight (BMI $\geq 85$ th centile), we applied IDF obesity criteria if there was central obesity ( $W C \geq 90$ th centile). In children aged $\leq 10$ years old, the criteria adopted by Boney et al. among children in the USA were used (10). Boney et al. defined MS as the presence of two or more of the following four criteria: obesity (BMI $\geq$ 85th centile), hypertension (SBP or DBP $\geq 95$ th centile for age), dyslipidemia TG $\geq 95$ th centile or $\mathrm{HDL}<5$ th centile for age), and glucose intolerance (FBG $>110 \mathrm{mg} / \mathrm{dl}$ or a 2 -h postprandial glucose level of $>140 \mathrm{mg} / \mathrm{dl}$ after a standard mixed meal).

Insulin resistance was determined by a homeostatic model assessment (HOMA-IR) (11). HOMA-IR was calculated by multiplying the fasting plasma insulin level $(\mathrm{mIU} / \mathrm{L})$ with the fasting plasma glucose level $(\mathrm{mmol} / \mathrm{L})$ and then dividing by 22.5 (11). Insulin resistance was defined as a HOMA-IR score $\geq$ 3.16. Hyperinsulinemia was defined as a fasting insulin level $>17$ $\mathrm{mIU} / \mathrm{L}(12,13)$.

\section{Sample Size Calculation}

Two-stage cluster random sampling method was used, with the cluster being schools. The number of public and private schools was selected randomly and proportionate to the number present in the city. Considering the mean prevalence of overweight/obesity among schoolchildren to be $28 \%$ and prevalence of MS among children with overweight/obesity to be $20 \%$ (from different studies), it was calculated that the prevalence 
of MS in normal schoolchildren would be $5.6 \%$ ( 0.28 multiplied by 0.20$)$. With an absolute error of $2 \%$, it was estimated that a total of 508 samples would be required for the study if conducted using simple random sample (14). Considering cluster random sampling design that was selected for the study, a design effect of four was used to arrive at a final minimum sample size of 2,032. An additional $10 \%$ sample was used considering the chances of non-responders, parents not giving consent, or chances of error in blood sample collection, etc. Thus, a total of 2,235 minimum number of samples were taken as the final sample size for screening MS.

\section{Statistical Analysis}

Data were analyzed using the statistical software STATA 13.0. Descriptive data were presented as number and proportions. Independent samples t-test was applied to compare the means, and the proportions were compared using chi-square test. Linear regression analysis was done using variables that were found to be significant on bivariate analysis and also those possible to have an influence on HOMA-IR. A $p<0.05$ was considered as statistically significant.

\section{RESULTS}

A total of 2,235 children were screened and 305 (13.6\%) children were excluded because of non-consent or unwillingness for blood sampling. A total of 1,930 children were screened for overweight/obesity based on BMI (Figure 1). Of the 1,930 children, $602(31.2 \%)$ were from government schools and $1,328(68.8 \%)$ were from private schools. A total of 545 children $(28.2 \%)$ were found to be overweight/obese [overweight $=383(19.83 \%)$, obese $=162(8.3 \%)]$. The prevalence of overweight/obesity in schoolchildren 6 to 16 years of age in government schools was $69 / 602(11.5 \%)$ and in private school was $476 / 1,328(35.8 \%)$. The male to female ratio was 1.27 $(305 / 240)$. Of the 545 children, 244 were 6 to $\leq 10$ years old [obesity $=70(28.7 \%)$, overweight $=174(71.3 \%)]$, and 301 were 11 to 16 years old [obesity $=92(30.6 \%)$, overweight $=209$ (69.4\%)]. The prevalence of central obesity (WC >90th centile) was $13.6 \%$ in children who were overweight $(n=52)$ and $68.4 \%$ in children who were obese $(n=111)$. The detailed analysis is provided in Table 1.

Cardiovascular disease, diabetes, obesity, and hypertension in the family were present in $42.7 \%$. Acanthosis nigricans was present in $46.4 \%$. A history of EBF for 6 months was present in $68.1 \%$. The liver was enlarged in $8.1 \%$. The detailed analysis is provided in Table 1.

The overall prevalence of metabolic syndrome in overweight/obese children was $21.8 \%(11 \%$ in 6 to $\leq 10$ years old and $30.6 \%$ in 11 to 16 years old). The prevalence of individual components/risk factors of MS is provided in Table 2. As can be seen, low HDL was the most common (22.6\%) and hyperglycemia was the least common $(12.8 \%)$ component/defining criteria for MS. Except for obesity, the risk factors were more common in girls than in boys. Only one adolescent had all the risk factors of MS.

A univariate analysis of each component of MS by potential predictive factors (age, gender, obesity, family history of CVD and NCD, and EBF at 6 months) was carried out. Subsequent multivariate models (Table 3 ) showed that female gender was not significantly associated in any of the components of MS. High $\mathrm{BP}$ was also not significantly associated with any of the variables (age, gender, family history of CVD and NCD, and EBF at 6 months). Central obesity (WC $>90$ th centile) was significantly

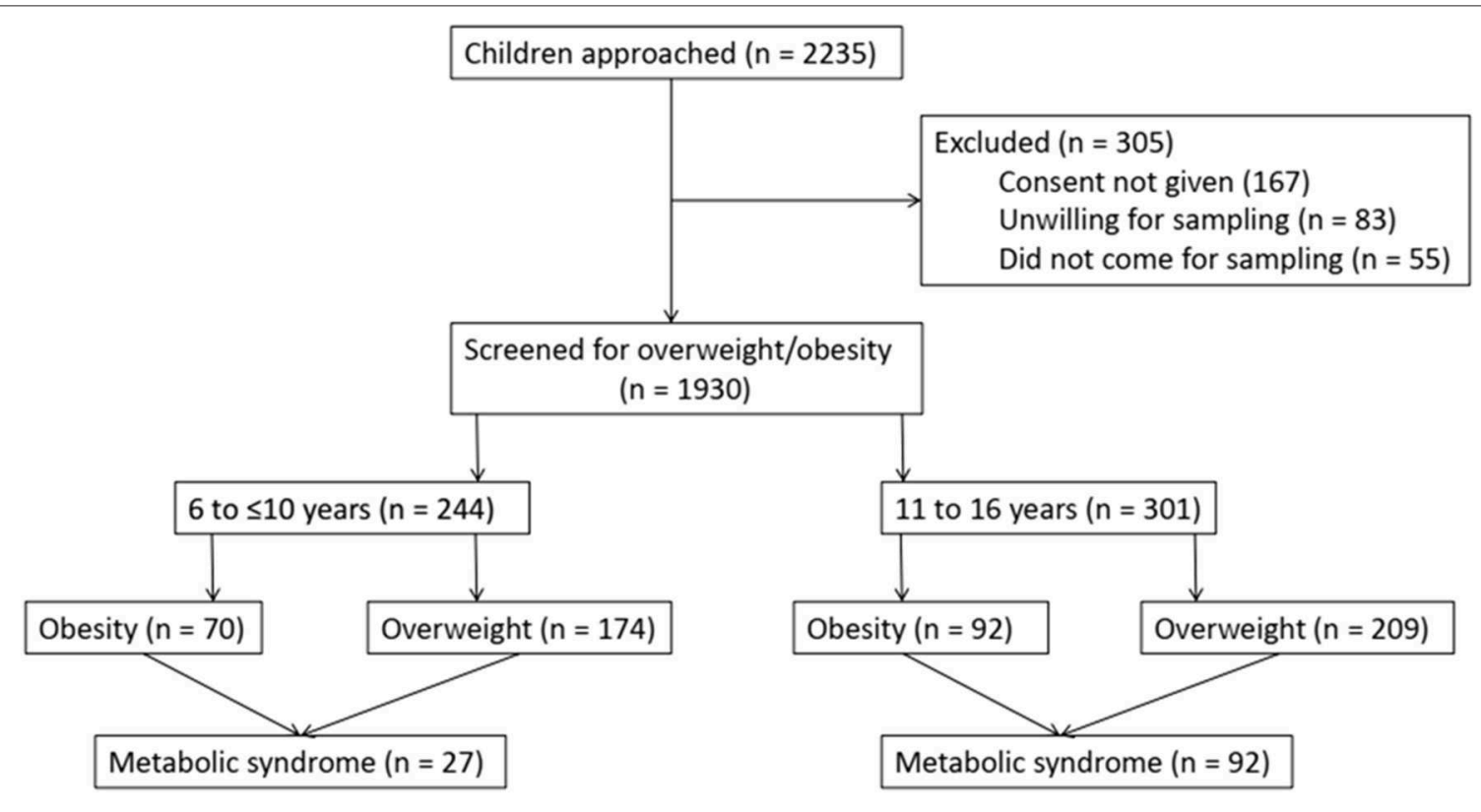

FIGURE 1 | Flow of this study's children. 
TABLE 1 | Anthropometric, clinical, and biochemical parameters among the study population.

\begin{tabular}{|c|c|c|c|c|c|}
\hline \multirow[t]{2}{*}{ Parameters } & \multicolumn{2}{|c|}{ MS Present } & \multicolumn{2}{|c|}{ MS absent } & \multirow[t]{2}{*}{$p$-value } \\
\hline & Mean & SEM & Mean & SEM & \\
\hline \multicolumn{6}{|l|}{ Type of schoola } \\
\hline Private & 104 & $21.8 \%$ & 372 & $78.2 \%$ & 0.98 \\
\hline Government & 15 & $21.7 \%$ & 54 & $78.3 \%$ & \\
\hline \multicolumn{6}{|l|}{$\operatorname{Sex}^{a}$} \\
\hline Male & 59 & $19.3 \%$ & 246 & $80.7 \%$ & 0.11 \\
\hline Female & 60 & $25.0 \%$ & 180 & $75.0 \%$ & \\
\hline \multicolumn{6}{|l|}{ Age group ${ }^{a}$} \\
\hline 6 to $\leq 10$ years old & 27 & $11.1 \%$ & 217 & $88.9 \%$ & $<0.01^{*}$ \\
\hline $11-16$ years old & 92 & $30.6 \%$ & 209 & $69.4 \%$ & \\
\hline Age (years) & 11.27 & 0.20 & 9.57 & 0.12 & $<0.01^{*}$ \\
\hline Weight (kg) & 50.56 & 1.14 & 39.76 & 0.60 & $<0.01^{\star}$ \\
\hline Height (cm) & 145.10 & 1.21 & 136.91 & 0.72 & $<0.01^{\star}$ \\
\hline $\mathrm{BMI}\left(\mathrm{KG} / \mathrm{M}^{2}\right)$ & 23.54 & 0.20 & 20.56 & 0.11 & $<0.01^{*}$ \\
\hline \multicolumn{6}{|l|}{ Blood pressure (mmHg) } \\
\hline Systolic BP & 121.98 & 0.54 & 113.16 & 4.50 & 0.3 \\
\hline Diastolic BP & 80.05 & 0.43 & 71.29 & 0.29 & $<0.01^{*}$ \\
\hline Waist circumference (cm) & 79.77 & 8.23 & 70.06 & 7.81 & $<0.01^{*}$ \\
\hline $\begin{array}{l}\text { Waist circumference } \\
>90 \text { th centile }\end{array}$ & 106 & $89 \%$ & 57 & $14 \%$ & $<0.01^{*}$ \\
\hline Hip circumference (cm) & 67.05 & 0.77 & 53.34 & 0.42 & $<0.01^{\star}$ \\
\hline \multicolumn{6}{|l|}{$\begin{array}{l}\text { Family history of NCD } \\
\text { and CVD }\end{array}$} \\
\hline Present & 65 & $27.9 \%$ & 168 & $72.1 \%$ & $<0.01^{\star}$ \\
\hline Absent & 54 & $17.3 \%$ & 258 & $82.7 \%$ & \\
\hline \multicolumn{6}{|l|}{ EBF for 6 months ${ }^{a}$} \\
\hline Present & 72 & $19.4 \%$ & 299 & $80.6 \%$ & $0.045^{\star}$ \\
\hline Absent & 47 & $27.0 \%$ & 127 & $73.0 \%$ & \\
\hline \multicolumn{6}{|l|}{$\begin{array}{l}\text { Biochemical } \\
\text { parameters }\end{array}$} \\
\hline FBG (mg/dl) & 99.34 & 0.54 & 83.51 & 0.30 & $<0.01^{\star}$ \\
\hline TG (mg/dl) & 160.10 & 1.55 & 110.91 & 1.10 & $<0.01^{\star}$ \\
\hline $\mathrm{HDL}(\mathrm{mg} / \mathrm{dl})$ & 35.80 & 0.29 & 44.11 & 0.15 & $<0.01^{\star}$ \\
\hline LDL (mg/dl) & 97.88 & 0.81 & 80.78 & 0.46 & $<0.01^{\star}$ \\
\hline Insulin (mIU/L) & 22.06 & 0.64 & 10.47 & 0.21 & $<0.01^{\star}$ \\
\hline HOMA_IR & 5.47 & 0.17 & 2.18 & 0.04 & $<0.01^{\star}$ \\
\hline \multicolumn{6}{|l|}{ Acanthosis nigricans $^{a}$} \\
\hline Present & 107 & $42.5 \%$ & 145 & $57.5 \%$ & $<0.01^{\star}$ \\
\hline Absent & 12 & $4.1 \%$ & 281 & $95.9 \%$ & \\
\hline \multicolumn{6}{|l|}{ Hepatomegalya } \\
\hline Present & 44 & $77.2 \%$ & 13 & $22.8 \%$ & $<0.01^{\star}$ \\
\hline Absent & 75 & $15.4 \%$ & 413 & $84.6 \%$ & \\
\hline
\end{tabular}

${ }^{1}$ Indicate numbers with proportion.

${ }^{*}$ p-value $<0.05$.

BMI, body mass index; FBG, fasting blood glucose; TG, triglyceride; HDL, high density lipoprotein; $L D L$, low density lipoprotein; SBP, systolic blood pressure; DBP, diastolic blood pressure; EBF, exclusive breastfeeding; HOMA-IR, indicates insulin resistance and calculated by multiplying insulin with fasting blood glucose; CVD, cardio-vascular disease; NCD, non-communicabledisease.

associated with age and family history of CVD and NCD. High FBG was significantly associated with age and central obesity. High triglyceride was associated with age, obesity, and family history of CVD and NCD. Low HDL cholesterol was significantly associated with a family history of CVD and NCD and absent EBF at 6 months. In the case of high blood pressure, no variable was qualified for the multivariate analysis.

The mean HOMA-IR in children with MS was 5.46 (insulin resistance defined as HOMA-IR score $\geq 3.16$ ) compared to 2.18 in those without MS. A linear regression analysis was done using variables that were found to be significant on bivariate analysis and also those possible to have an influence on HOMA-IR. The variables that were found to be significant were TG [RR 5.8 (95\% CI 4.7-7.4)], waist circumference [RR 3.2 (95\% CI 2.83.6)], diastolic BP [RR 3.5 (95\% CI 3.1-3.9)], systolic BP [RR $2.9(95 \%$ CI $2.4-3.5)$ ], and age ( $<10$ years old) [RR $0.34(95 \%$ CI $0.25-0.44)]$.

\section{DISCUSSION}

The present study from Eastern India (with a developing country setting) provided the prevalence of metabolic syndrome in schoolchildren 6-16 years of age. The results were surprising in that the overall prevalence was high $(21.8 \%)$, and around $11 \%$ of children $\leq 10$ years fulfilled the MS criteria. The overall prevalence of overweight/obesity in the study population was $28.2 \%$. Low HDL was found to be the most common single risk component of MS. Insulin resistance was higher in those with MS.

There have been various studies published worldwide on the prevalence of MS in children and adolescents (10, 1425). These are mainly hospital-based studies, with few being conducted in school or community settings $(10,16,19-21)$. Of the latter, only two previously published studies have provided the prevalence of MS in children $\leq 10$ years of age $(10,16)$. Of these two studies, one found the prevalence of MS in children aged $6-11$ years to be $21 \%$ if the mother had gestational diabetes mellitus (GDM) and to be $18 \%$ if the mother had no GDM (10). The other did not report the overall prevalence but reported the prevalence of individual risk factors in this age group in a general sample (not only in overweight/obese children) of schoolchildren (obesity $-6.3 \%$, elevated $\mathrm{BP}-10.4 \%$, hypertriglyceridemia-6\%, fasting hyperglycemia-2\%, and HDL_not reported) (16). A systematic review published in 2013 analyzed data published from year 2003 and found the median prevalence of MS to be $3.3 \%$ (range $0-19.2 \%$ ) in the general pediatric population, $11.9 \%$ (range $2.8-29.3 \%$ ) in children who were overweight, and $29.2 \%$ (range 10-66\%) in children who were obese (14).

The IDF criteria are most commonly used for the diagnosis of MS in the pediatric population (9). There are various other criteria available for defining pediatric MS that can falsely change the actual prevalence of MS (21). There is no standard definition for MS in children $\leq 10$ year of age, and we used the definition published previously by Boney et al. on children in the USA (10). Boney et al. used BMI instead of waist circumference to define obesity. To our utter surprise, we found that $11 \%$ of children in this age group are fulfilling two or more criteria of MS in addition to obesity. There has been a dramatic change in 
TABLE 2 | Prevalence of individual risk factors of the metabolic syndrome.

\begin{tabular}{|c|c|c|c|c|c|}
\hline & $\begin{array}{l}\text { Obesity*, } \\
\%(95 \% \mathrm{Cl})\end{array}$ & $\begin{array}{l}\text { Hyperglycemia, } \\
\%(95 \% \text { Cl) }\end{array}$ & $\begin{array}{l}\text { Hypertriglyceridemia, } \\
\quad \%(95 \% \mathrm{CI})\end{array}$ & $\begin{array}{l}\text { Low HDL, } \\
\%(95 \% \mathrm{Cl})\end{array}$ & $\begin{array}{l}\text { Elevated BP, } \\
\%(95 \% \mathrm{Cl})\end{array}$ \\
\hline Total & $29.7 \%(28.2-30.6)$ & $12.8 \%(11.8-16.2)$ & 20.8\% (19.2-21.6) & $22.6 \%(21.3-23.4)$ & $15.4 \%(13.5-18.8)$ \\
\hline \multicolumn{6}{|l|}{ Sex } \\
\hline Male & 29.8\% (27.8-30.7) & $13.1 \%(12.3-15.7)$ & $19.6 \%(18.7-21.4)$ & $21.6 \%(20.5-22.1)$ & $15.8 \%(14.3-17.2)$ \\
\hline Female & $29.2 \%(27.6-30.6)$ & $12.6 \%(11.2-15.5)$ & $21.4 \%$ (19.5-21.8) & $23.1 \%(21.7-23.8)$ & $14.7 \%(12.9-16.7)$ \\
\hline \multicolumn{6}{|l|}{ Age (Y) } \\
\hline $6-<8$ & 23.8\% (21.6-25.2) & $2.4 \%(1.9-4.7)$ & $18.7 \%(16.9-20.4)$ & $20.2 \%(18.7-21.9)$ & $12.4 \%(10.8-13.6)$ \\
\hline $8-<10$ & $31.1 \%(29.3-32.1)$ & $5.2 \%(3.8-7.5)$ & $19.9 \%(18.1-21.7)$ & $22.3 \%(19.6-13.5)$ & $16.2 \%(14.6-17.7)$ \\
\hline $10-<12$ & $31.2 \%(30.2-31.9)$ & $17.8 \%(16.7-19.1)$ & $21.3 \%$ (19.5-22.4) & $23.1 \%(20.8-24.4)$ & $18.4 \%(16.8-20.1)$ \\
\hline $12-<14$ & $31.1 \%(29.4-33.2)$ & $19.2 \%(18.1-21.4)$ & $21.9 \%$ (20.1-22.8) & $23.5 \%(21.1-24.6)$ & $18.9 \%(17.2-20.2)$ \\
\hline $14-16$ & $29.2 \%(27.8-30.7)$ & $19.4 \%(17.7-21.5)$ & $21.7 \%(19.8-22.4)$ & $22.9 \%(20.9-24.2)$ & $19.8 \%(18.1-21.2)$ \\
\hline \multicolumn{6}{|l|}{ BMI } \\
\hline Overweight & 70.3\% (68.6-71.4) & $4.6 \%(3.2-5.3)$ & $5.8 \%(5.1-7.1)$ & $7.4 \%(6.2-8.1)$ & $6.9 \%(5.9-8.2)$ \\
\hline Obesity & 29.7\% (28.2-30.6) & 28.3\% (26.7-29.5) & $34.5 \%$ (32.7-35.8) & $35.1 \%(34.3-36.4)$ & $27.2 \%(26.6-28.5)$ \\
\hline
\end{tabular}

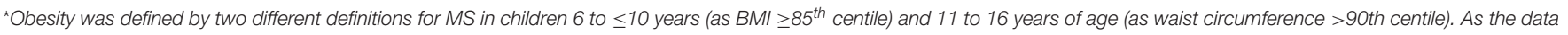

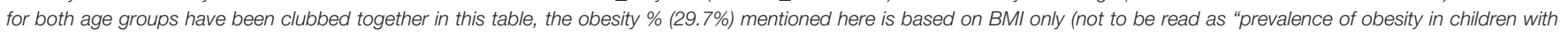
overweight is $70.3 \% "$ ). For prevalence of central obesity (waist circumference >90th centile), please refer to the "RESULTS" section and Table 1.

$\mathrm{Cl}$, confidence interval.

TABLE 3 | Multivariate analysis [odds ratios (95\% Cl)] for components of MS.

\begin{tabular}{|c|c|c|c|c|c|}
\hline Variables & WC $>$ 90th centile & High FBG & High triglyceride & Low HDL & High BP \\
\hline \multicolumn{6}{|l|}{ Age } \\
\hline$\leq 10$ years old & - & - & - & - & - \\
\hline$>10$ years old & $2.03(1.56-2.14)$ & $2.66(1.48-4.92)$ & $1.29(1.03-2.04)$ & $1.12(0.92-1.43)$ & $1.82(0.87-2.01)$ \\
\hline \multicolumn{6}{|l|}{ Gender } \\
\hline Male & - & - & - & - & - \\
\hline Female & $0.92(0.85-1.32)$ & $1.34(0.89-1.77)$ & 1.09 (0.91-1.23) & $1.12(0.76-1.52)$ & $1.14(0.88-1.3)$ \\
\hline \multicolumn{6}{|l|}{ Overweight } \\
\hline No & - & - & - & - & - \\
\hline Yes & 49.0 (26.7-99.2) & 3.28 (1.47-3.73) & 2.28 (1.69-3.43) & $1.53(0.81-2.01)$ & $1.42(0.99-2.06)$ \\
\hline \multicolumn{6}{|c|}{ Family History of NCD and CVD } \\
\hline Present & - & - & - & - & - \\
\hline Absent & 1.46 (1.28-2.23) & $1.0(0.81-1.13)$ & 1.89 (1.01-2.37) & 2.43 (1.41-3.02) & $1.14(0.77-1.96)$ \\
\hline \multicolumn{6}{|c|}{ EBF for 6 months } \\
\hline Present & - & - & - & - & - \\
\hline Absent & 1.08 (0.64-1.03) & $1.19(0.95-1.76)$ & $0.83(0.54-1.06)$ & $1.21(1.05-1.68)$ & $1.12(0.79-1.48)$ \\
\hline
\end{tabular}

Significant associations $(p<0.05)$ are shown in bold.

the lifestyle of students with the adoption of western diet, less outdoor activity, more screen time activity, and increase in stress due to study pressure at school as well as at home. All these factors potentially increase the risk of developing obesity and MS (26).

We included children who were overweight and obese and compared the risk factors for MS. As expected, the individual risk factors were significantly more common in those with obesity. Overweight, obesity, and MS were more common in children from private schools than those from government schools. Though our objective was not to study the factors underlying this observation, a possible explanation includes differences in the socio-economic status and the lifestyle of children coming from schools private and those who were from government schools. Compared to boys, girls had a slightly increased prevalence of individual components/risk factors of MS except obesity, and the reason may be the female sex hormones. A history of a cardiovascular disease, diabetes, obesity, and hypertension in the family was present in a significant number of children in this study. This might have added to the increased prevalence of MS in the study population as shown in previous studies $(14,18,25)$. Insulin resistance was more common in children with MS. This was also supported in the study by a higher prevalence of acanthosis nigricans in children 
with MS. A significant number of children also had acanthosis nigricans, reflected as an increase in insulin resistance as shown by increased HOMA-IR. Although a history of EBF for 6 months was present in $68.1 \%$, we could not find a decreased risk of MS linked to EBF. Hepatomegaly was present in $8.1 \%$ of the children, which was not confirmed by ultrasonography to be of fatty origin but is likely to be due to it. This is an important finding as it may develop in the future to non-alcoholic steatohepatitis, which is an important cause of chronic liver diseases in adults nowadays.

The definitions of MS in children have been extrapolated mostly from that of the adults, with the latter focusing on the central role of insulin in the development of MS $(27,28)$. In contrast to adults, there is no single definition of MS in pediatric literature $(10,16,19-21)$. Barriers to this include adult cutoffs or a single set of cutoff points across all age groups, lack of normative data for plasma insulin level, pubertal insulin resistance, and lack of central obesity (waist) cutoff points in majority of the study settings. In the present study, children with hyper-insulinemia were found to have significantly higher values of other common cardiovascular risk factors (TG, BP, and WC). This has implications for the screening costs of children identified as overweight or obese. Early detection of hyperinsulinemia may indicate changes in metabolic profile before other more commonly measured cardiovascular risk factors are found outside the recommended ranges. However, it also has to be remembered that clustering of several metabolic indicators that are potentially of greater clinical significance would be ignored if hyper-insulinemia alone is used as a marker of MS in children (29).

An additional finding in our study was the high prevalence of central obesity (WC $>90$ th centile) even in those being overweight (as defined by BMI). More data on children are required on the morbidity-related definition of overweight using WC, which probably is a better predictor of metabolic risk than BMI $(13,16)$. A study on pre-pubertal children in the USA has suggested a single WC cutoff of $71 \mathrm{~cm}$ as a risk factor for adverse CVD risk factor profile, which may be true as the mean WC in the present study was too high (30).

The present study has some limitations. First, the use of western data cutoffs to define MS in children $\leq 10$ years old may not truly reflect the prevalence in this age group. Second, we did not perform oral glucose tolerance test to define impaired glucose tolerance or type 2 diabetes mellitus. Third, we did not collect data regarding pubertal changes, physical activity, and dietary

\section{REFERENCES}

1. WHO. Overweight Obesity. WHO Fact Sheets. Available online at: https:// www.who.int/news-room/fact-sheets/detail/obesity-and-overweight (Accessed July 19, 2019).

2. Cole TJ, Bellizzi MC, Flegal KM, Dietz WH. Establishing a standard definition for child overweight and obesity worldwide: international survey. BMJ. (2000) 320:1240-3. doi: 10.1136/bmj.320.7244.1240

3. Ranjani H, Mehreen TS, Pradeepa R, Anjana RM, Garg R, Anand K, et al. Epidemiology of childhood overweight \& obesity in India: a systematic review. Indian J Med Res. (2016) 143:160-74. doi: 10.4103/0971-5916.180203 pattern. Finally, being a cross-sectional study, it does not provide information about causality.

\section{CONCLUSIONS}

The present study found a higher prevalence of MS and insulin resistance in schoolchildren from Eastern India who were overweight/obese. The worsening epidemic of obesity and its associated long-term health risks highlight the need for a workable, consistent definition of MS in children to enable the investigation of prevalence and of both short- and long-term health outcomes.

\section{DATA AVAILABILITY STATEMENT}

All datasets generated for this study are included in the article/supplementary material.

\section{ETHICS STATEMENT}

The studies involving human participants were reviewed and approved by the Institute Ethics Committee of AIIMS Bhubaneswar. Written informed consent/assent was collected from the children or the children's parents/guardians. All methods and experimental protocols in this study were conducted in accordance with the approved protocols and Ethics Committee's existing guidelines. Written informed consent to participate in this study was provided by the participants' legal guardian/next of kin.

\section{AUTHOR CONTRIBUTIONS}

RD conceived and designed the experiment. RD, MM, SP, and PR performed the experiment and analyzed the data. AS and SM provided comments and technical advice. RD, AS, SP, and SM wrote the manuscript. All the authors have discussed the results, commented on the manuscript, and agreed to be accountable for all aspects of the work in ensuring that questions related to the accuracy or integrity of any part of the work are appropriately investigated and resolved. RD will act as guarantor.

\section{FUNDING}

This study was funded by the Institute Intramural Grant of AIIMS Bhubaneswar [Grant No. P/IM-F/Pedia/15/29 (dated - 2/5/2016)].

4. Khadilkar VV, Khadilkar AV, Borade AB, Chiplonkar SA. Body mass index cut-offs for screening for childhood overweight and obesity in Indian children. Indian Pediatr. (2012) 49:29-34. doi: 10.1007/s13312-0120011-y

5. Vikram NK, Misra A, Pandey RM, Dwivedi M, Luthra K. Adiponectin, insulin resistance, and C-reactive protein in postpubertal Asian Indian adolescents. Metabolism. (2004) 53:1336-41. doi: 10.1016/j.metabol.2004.05.010

6. Khalil A, Gupta S, Madan A, Venkatesan M. Lipid profile norms in Indian children. Indian Pediatr. (1995) 32:1177-80.

7. Kuriyan R, Thomas T, Lokesh DP, Sheth NR, Mahendra A, Joy R, et al. Waist circumference and waist for height percentiles in urban 
South Indian children aged 3-16 years. Indian Pediatr. (2011) 48:765-71. doi: 10.1007/s13312-011-0126-6

8. Flynn JT, Kaelber DC, Baker-Smith CM, Blowey D, Carroll AE, Daniels SR, et al. Clinical practice guideline for screening and management of high blood pressure in children and adolescents. Pediatrics. (2017) 140:e20171904. doi: 10.1542/peds.2017-1904

9. Zimmet P, Alberti KG, Kaufman F, Tajima N, Silink M, Arslanian S, et al. The metabolic syndrome in children and adolescents - an IDF consensus report. Pediatr Diabetes. (2007) 8:299-306. doi: 10.1111/j.1399-5448.2007.0 0271.x

10. Boney CM, Verma A, Tucker R, Vohr BR. Metabolic syndrome in childhood: association with birth weight, maternal obesity, and gestational diabetes mellitus. Pediatrics. (2005) 115:e290-6. doi: 10.1542/peds. 2004-1808

11. Matthews DR, Hosker JP, Rudenski AS, Naylor BA, Treacher DF, Turner RC. Homeostasis model assessment: insulin resistance and beta-cell function from fasting plasma glucose and insulin concentrations in man. Diabetologia. (1985) 28:412-9. doi: 10.1007/bf00280883

12. Yin J, Li M, Xu L, Wang Y, Cheng H, Zhao X, et al. Insulin resistance determined by Homeostasis Model Assessment (HOMA) and associations with metabolic syndrome among Chinese children and teenagers. Diabetol Metab Syndr. (2013) 5:71. doi: 10.1186/1758-5996-5-71

13. Rodea-Montero ER, Evia-Viscarra ML, Apolinar-Jiménez E. Waist-to-height ratio is a better anthropometric index than waist circumference and BMI in predicting metabolic syndrome among obese Mexican adolescents. Int $J$ Endocrinol. (2014) 2014:195407. doi: 10.1155/2014/195407

14. Friend A, Craig L, Turner S. The prevalence of metabolic syndrome in children: a systematic review of the literature. Metab Syndr Relat Disord. (2013) 11:71-80. doi: 10.1089/met.2012.0122

15. Singh R, Bhansali A, Sialy R, Aggarwal A. Prevalence of metabolic syndrome in adolescents from a north Indian population. Diabet Med. (2007) 24:195-9. doi: 10.1111/j.1464-5491.2007.02066.x

16. Chen F, Wang Y, Shan X, Cheng H, Hou D, Zhao X, et al. Association between childhood obesity and metabolic syndrome: evidence from a large sample of Chinese children and adolescents. PLoS ONE. (2012) 7:e47380. doi: 10.1371/journal.pone. 0047380

17. Lafortuna CL, Adorni F, Agosti F, De Col A, Sievert K, Siegfried W, et al. Prevalence of the metabolic syndrome among extremely obese adolescents in Italy and Germany. Diabetes Res Clin Pract. (2010) 88:14-21. doi: 10.1016/j.diabres.2010.01.008

18. Vukovic R, Zdravkovic D, Mitrovic K, Milenkovic T, Todorovic S, Vukovic A, et al. Metabolic syndrome in obese children and adolescents in Serbia: prevalence and risk factors. J Pediatr Endocrinol Metab. (2015) 28:903-9. doi: 10.1515/jpem-2014-0533

19. Suarez-Ortegón MF, Aguilar-de Plata C. Prevalence of metabolic syndrome in children aged 5-9 years from southwest colombia: a cross-sectional study. World J Pediatr. (2016) 12:477-83. doi: 10.1007/s12519-0160008-z

20. Papoutsakis C, Yannakoulia M, Ntalla I, Dedoussis GV. Metabolic syndrome in a Mediterranean pediatric cohort: prevalence using International Diabetes
Federation-derived criteria and associations with adiponectin and leptin. Metabolism. (2012) 61:140-5. doi: 10.1016/j.metabol.2011.06.006

21. Costa RF, Santos NS, Goldraich NP, Barski TF, Andrade KS, Kruel LF. Metabolic syndrome in obese adolescents: a comparison of three different diagnostic criteria. J Pediatr. (2012) 88:303-9. doi: 10.2223/JPED.2200

22. López-Capapé M, Alonso M, Colino E, Mustieles C, Corbatón J, Barrio R. Frequency of the metabolic syndrome in obese Spanish pediatric population. Eur J Endocrinol. (2006) 155:313-9. doi: 10.1530/eje.1.02206

23. Druet C, Dabbas M, Baltakse V, Payen C, Jouret B, Baud C, et al. Insulin resistance and the metabolic syndrome in obese French children. Clin Endocrinol. (2006) 64:672-8. doi: 10.1111/j.1365-2265.2006.02526.x

24. Weiss R, Dziura J, Burgert TS, Tamborlane WV, Taksali SE, Yeckel CW, et al. Obesity and the metabolic syndrome in children and adolescents. $N$ Engl $J$ Med. (2004) 350:2362-74. doi: 10.1056/NEJMoa031049

25. Šimunović M, BoŽić J, Milić L, Unić I, Škrabić V. The prevalence of metabolic syndrome and cardiovascular risk factors in obese children and adolescents in dalmatia: a hospital based study. Int J Endocrinol. (2016) 2016:1823561. doi: $10.1155 / 2016 / 1823561$

26. Armoon B, Karimy M. Epidemiology of childhood overweight, obesity and their related factors in a sample of preschool children from Central Iran. BMC Pediatr. (2019) 19:159. doi: 10.1186/s12887-019-1540-5

27. Chen W, Srinivasan SR, Elkasabany A, Berenson GS. Cardiovascular risk factors clustering features of insulin resistance syndrome (Syndrome X) in a biracial (Black-White) population of children, adolescents, and young adults: the Bogalusa Heart Study. Am J Epidemiol. (1999) 150:667-4. doi: 10.1093/oxfordjournals.aje.a010069

28. Raitakari OT, Porkka KV, Ronnemaa T, Knip M, Uhari M, Akerblom HK et al. The role of insulin in clustering of serum lipids and blood pressure in children and adolescents. The cardiovascular risk in young finns study. Diabetologia. (1995) 38:1042-50. doi: 10.1007/bf00402173

29. Misra A, Vikram N, Arya S, Pandey RM, Dhingra V, Chatterjee A et al. High prevalence of insulin resistance in postpubertal Asian Indian children is associated with adverse truncal body fat patterning, abdominal adiposity and excess body fat. Int J Obes Relat Metab Disord. (2004) 28:1217-26. doi: $10.1038 /$ sj.ijo.0802704

30. Higgins PB, Gower BA, Hunter GR, Goran MI. Defining healthrelated obesity in prepubertal children. Obesity Res. (2001) 9:233-40. doi: 10.1038/oby.2001.27

Conflict of Interest: The authors declare that the research was conducted in the absence of any commercial or financial relationships that could be construed as a potential conflict of interest.

Copyright $\odot 2020$ Das, Mangaraj, Panigrahi, Satapathy, Mahapatro and Ray. This is an open-access article distributed under the terms of the Creative Commons Attribution License (CC BY). The use, distribution or reproduction in other forums is permitted, provided the original author(s) and the copyright owner(s) are credited and that the original publication in this journal is cited, in accordance with accepted academic practice. No use, distribution or reproduction is permitted which does not comply with these terms. 